\title{
Spectrum of Neonatal Pneumothorax at a Tertiary Care Hospital of Bangladesh : A Retrospective Observational Study.
}

\author{
Md Abdul Mannan ${ }^{1 *}$, Sanjoy Kumar Dey², Nasim Jahan³, Shahed Iqbal ${ }^{4}$, SM Rezaul Karim5, Navila Ferdous ${ }^{6}$
}

\begin{abstract}
:
Introduction: Pneumothorax occurs more frequently in the neonatal period than in any other period of life \& is associated with increased mortality and morbidity. Several risk factors for pneumothorax, including respiratory pathology, invasive and non-invasive respiratory support \& predictors of mortality have been described.

Objective: To evaluate the prevalence of pneumothorax, to identify underlying causes \& to describe the clinical characteristics, management and outcome of neonates with pneumothorax, as well as to identify predictors of mortality in these neonates.

Methods: A retrospective chart review of neonatal records included all neonates hospitalized in the NICU of 'Ad-din Women's Medical College' Dhaka, between January 2016 \& December 2017 with the diagnosis of pneumothorax. The collected data included: demographics \& perinatal data, characteristics of pneumothorax, classification, treatment \& clinical outcomes. All statistical analyses were performed using the Statistical Package for Social Sciences (SPSS) version 16.

Results: Our study included 83 neonates, of whom 48 were male (57.83\%) \& 60 (72.29\%) born by lower uterine caesarean section (LUCS). Median gestational age(GA) was 36 (32-41) weeks \& the median birth weight(BW) was 2,558 (1500-3800) grams. The prevalence of neonatal Pneumothorax in our centre was $2.60 \%$ \& that of Spontaneous Pneumothorax was $1.53 \%$. The analysis of perinatal data showed statistically significant differences in APGAR score at 5th minute $(p=<0.00001) \&$ in resuscitation at birth $(p<0.00001)$. Pneumothorax was significantly associated with RDS, pneumonia, Meconium aspiration syndrome (MAS) \& Perinatal asphyxia (PNA), $(p=0.235893)$ and all $(n=6)$ death were observed in neonates who had coexisting diseases, $(p=0.00226)$. Forty nine $(59.04 \%)$ was $S P(p=$ 0.002) \& mainly observed in the right lung (77.11\%( ( $p=0.00011)$. To treat the pneumothoraces, $64(77.11 \%)$ neonates only received oxygen therapy, 16 (19.28\%) neonate needed MV along with chest tube (CT) drain, 02(2.41\%) thoracentesis with needle aspiration, and $01(1.20 \%)$ needle aspiration \& chest tube (CT) drain $(p<0.00001)$. Clinical data suggest that complications such as sepsis, severe hypotension, Necrotizing enterocolitis (NEC), DIC, Intraventricular haemorrhage (IVH) can negatively affect immediate outcomes $(p=0.00025)$. The mortality rate was $7.23 \%$. All the mortalities observed in neonates who got respiratory support with mechanical ventilation (MV) along with CT insertion $(p=<0.00001)$. Hypotension, sepsis, DIC, IVH, MV and thoracentesis followed by a CT insertion were found to be predictors of mortality in neonates with pneumothorax.
\end{abstract}

Conclusion: NP may develop during the neonatal period, especially in the presence of underlying clinical conditions, and neonates with pneumothorax managed with CT drain and respiratory support (MV), despite treatment have a high mortality rate.

Keywords: Pneumothorax, neonates, chest tube (CT) drain, mechanical ventilation (MV).

\section{Introduction:}

Pneumothorax is a collection of air between the lung and the chest wall that develops when air leaks out of the lung. Pneumothorax is one of the most common air leak syndromes that occurs more frequently in the neonatal period than in any other period of life and is a life-threatening condition associated with a high incidence of morbidity and mortality ${ }^{1}$. It has been suggested that early recognition and treatment are beneficial to avoid damage as a result of hypoxemia, hypercapnia \& impaired venous return ${ }^{1,2}$. A pneumothorax begins with the rupture of an over distended tiny alveoli. Gas from a ruptured alveolus escapes into the interstitial spaces of the lung, where it may cause interstitial emphysema or dissect along the peribronchial and perivascular connective tissue sheaths to the hilum of lung and subsequently into the pleural space, causing pneumothorax \& less commonly pneumomediastinum, pneumoperitoneum and subcutaneous emphysema, altogether known as air leak syndromes ${ }^{3,4}$. Pneumothorax is a relatively frequent critical situation in the Neonatal Intensive Care Unit (NICU). It is classified into primary pneumothorax (without any obvious lung diseases) and secondary pneumothorax (due to underlying lung pathology or associated with precipitating factors $^{1,5}$. Spontaneous pneumothorax (SP) is a form of primary pneumothorax in neonates. It usually occurs in the absence of inciting risk factors at birth ${ }^{1}$. The mechanism is related to maladaptive transition after birth. The presence of persistently high or unequal transpulmonary inflating pressure in the alveoli during the transition period results in rupture of alveoli into the pleural space and produces a spontaneous pneumothorax ${ }^{6}$. The incidence of radiologic SP is $1 \%$ to $2 \%$ and symptomatic SP is $0.05 \%$ to $1 \%$ in all live births and in very low birth weight (VLBW) neonates this rate can achieve $3.8 \%$ to $9 \%{ }^{1,7,8}$. The incidence rate can increase to up to $30 \%$ 
in patients who have concurrent underlying lung disease or who require mechanical ventilation ${ }^{9,}{ }^{10}$. In symptomatic pneumothorax, over $40 \%$ observed in the presence of respiratory distress syndrome ${ }^{11,12}$. It is more common in neonates who are treated with nasal continuous positive airway pressure (nCPAP), or who are using a mechanical ventilator and mortality rates have varied from $20 \%$ to $38 \%$, 12,13 . Several risk factors for pneumothorax have been described and include among others immaturity, low birth weight neonates, male sex, neonate born by cesarean section, the presence of respiratory distress syndrome(RDS) or post surfactant treatment, meconium aspiration syndrome (MAS) requiring resuscitation after birth, pneumonia, severe perinatal asphyxia (PNA) requiring vigorous resuscitation at birth, invasive and non-invasive respiratory support like nasal continuous positive pressure ventilation (nCPAP), mechanical ventilation (MV), pulmonary hypoplasia $(\mathrm{PH})$, neonates with urinary tract anomalies, or oligohydramnions, chorioamnionitis $^{14,15}$. For moderate-late preterm infants, risk factors also include high birth weight, male gender, \& rupture of membranes longer than 24 hours ${ }^{15}$. Common clinical manifestations of pneumothorax are respiratory distress (RD) signs (Tachypnea, flaring, cyanosis). Hypoxemia and hypercapnia are usually observed in arterial blood gases. In some cases, there is a mediastinal shift that compromises the cardiovascular system and carries a significant risk of an impaired outcome and death. Unilateral tension pneumothorax results in impaired ventilation not only in the ipsilateral lung but also in the contralateral lung owing to a shift in the mediastinum toward the contralateral side. Compression of the vena cava and torsion of the great vessels may interfere with venous return, as well as systemic hypotension and cardiac arrest. It is, therefore, essential to recognize these risk neonates in order to prevent and treat properly this critical situation ${ }^{1,3}$. The diagnosis of pneumothorax relies on clinical judgment, transillumination and chest radiogram ${ }^{16}$. The treatment of neonatal pneumothorax is not fully defined. Three approaches are the

1. Professor \& Head of Neonatology, Ad-din Women's Medical College Hospital, Dhaka-1217, Bangladesh.

2. Associate Professor Prof. of Neonatology, BSMMU, Dhaka, Bangladesh.

3. Consultant of Pediatrics and Neonatology, Asgar Ali Hospital, Dhaka, Bangladesh;

4. Associate professor of pediatrics, Chattagram Maa Shishu-O-General Hospital, Chattagram, Bangladesh.

5. Associate Professor \& Head of Pediatric Surgery, Ad-din Women's Medical College Hospital, Dhaka-1217, Bangladesh

6. Assistant Professor of Neonatology, Ad-din Women's Medical College Hospital, Dhaka-1217, Bangladesh.

\section{*Corresponding Author:}

Professor. Dr. Md Abdul Mannan Professor \& Head of Neonatology Ad-din Women's Medical College Hospital, Dhaka-1217, Bangladesh. E-mail: dr_amannan@yahoo.com common practice in NICUs. The expectant approach for small and asymptomatic pneumothorax, and active intervention to a significant one, such as needle (18-20G) aspiration and thoracic drainage ${ }^{17,18}$. Needle aspiration is an option in cases of mild to moderate pneumothorax when the infant is hemodynamically stable. In hypertensive (tension) pneumothoraces the common therapeutic approach is chest tube placement ${ }^{3}$.

\section{Objective:}

The aim of this study was to evaluate the prevalence, to identify underlying causes and to describe the clinical characteristics, management and outcome of neonates with pneumothorax as well as to identify the predictor factors of mortality in these neonates.

\section{Material and methods:}

We retrospectively reviewed the medical records of all neonates hospitalized in neonatal intensive care unit (NICU) of Ad-din Women's Medical College,Dhaka, between January 2016 and December 2017, with the diagnosis of pneumothorax. Diagnosis of pneumothorax was suspected based on physical examination, clinical symptoms and confirmed by chest X-ray. Inclusion criteria included: all (inborn and outborn) neonates admitted to the NICU presented with respiratory distress and confirmed the pneumothorax on chest X-ray. A pediatric radiologist, blinded to the therapeutic approach, read all chest X-rays. There were no exclusion criteria for the study. All data were collected from the hospital medical records of the patients. These data includes: neonatal demography like gestational age (GA), gender, birth weight (BW), mode of delivery, underlying medical conditions, age of appearance of pneumothorax, type of respiratory support like need for oxygen therapy, nasal continuous positive airway pressure (nCPAP), conventional mechanical ventilation (MV) and high frequency oscillation ventilation (HFOV) use and immediate outcome i.e. survival or death. Pneumothorax characteristics were also obtained (day of life and the duration of the pneumothorax) and classified as primary or spontaneous and secondary; iatrogenic; and hypertensive (or tension). We defined pneumothorax as primary spontaneous if it occurred without obvious cause or occurs in the absence of inciting risk factors; as secondary if there was an underlying pathology or associated with precipitating factors and as iatrogenic if it was caused by a medical ,surgical or clinical procedure like endotracheal (ET) intubation. Hypertensive or tension pneumothorax was considered whenever a mediastinal shift was observed. Data about treatment, neonatal morbidity and mortality were also collected. Pneumothoraces were diagnosed by chest radiography and the type of pneumothorax was assessed according to clinical setting and medical history ${ }^{1}$. Gestational age was assessed by post-menstrual age, ultrasound examination or the New Ballard Score (in the absence of obstetrical indexes) ${ }^{19,20}$. By plotting weight vs. gestational age, each neonate was classified at birth as Appropriate for gestational age (AGA) those birth weight (BW) in between $10^{\text {th }}$ to $90^{\text {th }}$ percentile and Small for gestational age (SGA) was defined as a birth weight below the 
$10^{\text {th }}$ percentile and large for gestational age (LGA) was defined as BW $>90^{\text {th }}$ percentile of Fenton's growth charts ${ }^{21}$. Our NICU has a protocol for positive pressure ventilation that includes different ventilatory strategies according to different lung diseases and favors the use of permissive hypercapnia. For the very low birth weight neonates' nCPAP just after birth is the preferable mode of ventilation ${ }^{22}$. Nasal CPAP is performed using Infant Flow (Medin, Sindi, Germany), for invasive mechanical ventilation (MV) we used Babylog ${ }^{\circledR}$ (Dräger, Germany) or SLE 500 (UK). HFOV was performed as rescue ventilation (SLE 5000, UK). Sepsis was considered in the presence of a positive blood culture, combined with clinical and laboratory parameters ${ }^{23}$. RDS was defined based on the European guidelines ${ }^{24}$ and Transient tachypnea of the newborn (TTN) was diagnosed according to the criteria of Machado and Fiori ${ }^{25}$. Pneumonia was diagnosed based on combination of clinical, radiological and laboratory parameters ${ }^{26}$. Meconium aspiration syndrome (MAS) was characterized based on El Shahed's criteria ${ }^{27}$. Pulmonary hypoplasia ( $\mathrm{PH})$ was defined according to clinical, radiologic, and pathologic criteria ${ }^{28}$. Perinatal asphyxia (PNA) defined based on criteria that was set by American College of Pediatrics (AAP) and American college of Obstetrics and Gynecology (ACOG) ${ }^{29}$. Hypotension was defined according to Cayabyab et. $\mathrm{al}^{30}$. Intraventricular hemorrhage (IVH) was defined according to Papile ${ }^{31}$ and Volpe ${ }^{32}$ (before and after 2010, respectively), intraventricular bleeding with ventricular dilatation is classified as IVH- 3 and with parenchymal involvement as IVH- 4. Necrotizing enterocolitis (NEC) was defined by clinical findings and radiological features, according to the modified Bell criteria ${ }^{33}$.

All statistical analyses were performed using the Statistical Package for Social Sciences (SPSS) version 16. Chi-Square test was used to see the significance between the groups. A p-value less than $0.05(\mathrm{p}<.05)$ is considered as statistically significant.

\section{Results:}

Medical charts of eighty three $(n=83)$ neonates, admitted between 1st January, 2016 to 31st December, 2017 with a diagnosis of pneumothorax were reviewed. Based on a total number of 3184 (1636 in year 2016 and 1548 in year 2017) admission during the study period, the prevalence of pneumothorax was $2.60 \%$, varying from $2.81 \%(\mathrm{n}=46)$ cases in 2016 to $2.39 \%(n=37)$ cases in 2017 and that of spontaneous pneumothorax (SP ) was $1.53 \%(n=49)$ at our centre.

Our study included 83 neonates, of whom 25 were preterm $(30.12 \%), 58$ were term $(69.88 \%) ; 34$ neonates were born with low birth weight $(40.96 \%), 49$ were with normal birth weight $(59.04 \%), 68$ were appropriate for gestational age $(81.93 \%)$ and 15 were small for gestational age (18.07\%). There were $48(57.83 \%)$ male and 35 (42.17\%) female; male-female ratio was $1.37: 1$. Their median gestational age was $36(32-41)$ weeks and the median birth weight was 2,558 (1500-3800) grams. Twenty three (23) neonates (27.71\%) were delivered normally through vaginal (NVD) route and 60 neonates $(72.29 \%)$ were by lower uterine caesarean section
(LUCS); 65 neonates were inborn (78.31\%) and 18 neonates were outborn $(21.69 \%)$; 8 neonate's $(9.64 \%)$ APGAR score at 5 minutes was $<7$ and score of 75 neonates $(90.36 \%)$ was over 7 at 5 minutes of birth ; 64 neonates $(77.11 \%)$ did not require any or minimal resuscitation at birth like oro-pharyngeal (OP) suction or blow by oxygen, 13 neonates $(15.66 \%)$ required positive pressure ventilation (PPV) i.e. bag and mask ventilation (BMV) and 6 neonates (7.23\%) required full resuscitation including endotracheal (ETT) intubation at birth. A total of 83 neonates, survival rate were higher in term (65.06\%), NBW (55.42\%), AGA (75.90\%), male (54.22\%), caesarian section $(67.47 \%)$, inborn $(73.49 \%)$ neonates and the neonates with Apgar score $>7(87.95 \%)$ and had required no or minimal resuscitation $(77.11 \%)$ respectively.

The analysis of demographic and perinatal data of different groups, showed statistically significant differences in APGAR score at 5 th minute $(\mathrm{p} .<0.00001) \&$ in resuscitation at birth $(\mathrm{p}$ $<0.00001$ ), \& data of other groups showed statistically insignificant, as shown in Table- I.

A total $34(40.96 \%)$ neonates with pneumothorax had coexisting underlying cause and 49 (59.04\%) neonates had no coexisting diseases. Among the coexisting diseases, RDS $(24.10 \%)$ was most common followed by pneumonia $(8.43 \%)$, meconium aspiration syndrome $(4.82 \%)$, and perinatal asphyxia (3.61\%), there is no significant difference among the groups in aspect of these mentioned diseases $(\mathrm{p}=$ $0.235893)$ showed in Table II. All $(n=6)$ death were observed in neonates with pneumothorax who had coexisting diseases, $(p=0.00226)$ shown in Table III.

Table IV shows the characteristics and treatment of pneumothoraces. There were primary spontaneous in 49 $(59.04 \%)$ neonates and secondary in $34(40.96 \%)$ neonates, ( $p$ $=0.002)$. We observed over two thirds $(77.11 \%)$ pneumothoraces in the right lung, one fifth $(19.28 \%)$ in the left lung and rest $(3.6 \%)$ of were bilateral, $(p=0.0001)$. Out of 83 neonates, 60 (72.29\%) neonates developed pneumothorax $\leq 48$ hours post delivery and $23(27.71 \%)$ neonates developed 48 hours after delivery $(\mathrm{p}=0.205)$. To treat the pneumothoraces, $64(77.11 \%)$ neonates were treated only with oxygen therapy under oxyhood, 16 (19.28\%) neonate needed thoracentesis with needle aspiration, chest tube drain and MV, 02(2.41\%) needs thoracentesis with needle aspiration, $01(1.20 \%)$ thoracentesis with needle aspiration and chest tube $(\mathrm{CT})$ drain, $(\mathrm{p}<0.00001)$. All patients treated with thoracentesis with needle decompression, chest tube drain and MV also received oxygen therapy. Actually, thoracentesis with needle aspiration was performed in 19 (22.89\%) pneumothoraces, but 17 of them also had to be chest tube drained.

Table $\mathrm{V}$ denotes the outcome on the basis of clinical complications and management data. A total 27 (32.53\%) neonates observed different complications during hospital stay, of which sepsis observed in 17 (20.48\%) neonates, severe hypotension in $07(8.43 \%)$, sepsis with NEC in 01 (1.20\%), NEC with disseminated intravascular coagulation (DIC) in $01(1.20 \%)$, sepsis with DIC \& IVH in $01(1.20 \%)$ neonate and out of them 21 neonates recovered. No 
complications encountered in $56(67.47 \%)$ neonates, all of them survived $(\mathrm{p}=0.00025)$.

Table VI shows distribution and immediate outcome of neonatal pneumothorax on the basis of ventilatory support.
Out of 83 neonates, 16 neonates required the ventilatory support along with chest tube drainage, of them $10(62.50 \%)$ survived. No death observed in the neonates of whom didn't require ventilatory support $(\mathrm{p}=<0.00001)$.

Table I: Distribution of the neonates according to neonatal characteristics \& perinatal data

\begin{tabular}{|c|c|c|c|c|}
\hline \multirow[t]{3}{*}{ Variables } & \multicolumn{3}{|c|}{ Outcome of treatment } & \multirow{3}{*}{$\mathrm{P}$ value } \\
\hline & Total, n (\%) & Survived, n (\%) & Expired, n (\%) & \\
\hline & $83(100.00)$ & 77 (92.77) & $06(7.23)$ & \\
\hline \multicolumn{5}{|l|}{ Gestational age in weeks } \\
\hline Preterm $(<37)$ & $25(30.12)$ & $23(27.71)$ & $02(2.41)$ & 0.858 \\
\hline Term $(\geq 37)$ & $58(69.88)$ & $54(65.06)$ & $04(4.82)$ & \\
\hline \multicolumn{5}{|l|}{ Weight in grams } \\
\hline LBW (<2500 gm) & $34(40.96)$ & $31(37.35)$ & $03(3.61)$ & 0.640 \\
\hline NBW (2500-3999gm) & $49(59.04)$ & $46(55.42)$ & $03(3.62)$ & \\
\hline \multicolumn{5}{|l|}{ Weight vs. gestational age } \\
\hline AGA & $68(81.93)$ & $63(75.90)$ & $05(6.03)$ & 0.925 \\
\hline SGA & $15(18.07)$ & $14(16.87)$ & $01(1.20)$ & \\
\hline \multicolumn{5}{|l|}{ Gender } \\
\hline Male & $48(57.83)$ & $45(54.22)$ & $03(3.61)$ & 0.686 \\
\hline Female & $35(42.17)$ & $32(38.55)$ & $03(3.62)$ & \\
\hline \multicolumn{5}{|l|}{ Method of delivery } \\
\hline Vaginal (NVD) & $23(27.71)$ & $21(25.30)$ & $02(2.41)$ & 0.749 \\
\hline Caesarean section & $60(72.29)$ & $56(67.47)$ & $04(4.82)$ & \\
\hline \multicolumn{5}{|l|}{ Place of delivery } \\
\hline Inborn & $65(78.31)$ & $61(73.49)$ & $04(4.82)$ & 0.472 \\
\hline Outborn & $18(21.69)$ & $16(19.28)$ & $02(2.41)$ & \\
\hline \multicolumn{5}{|l|}{ Apgar Score } \\
\hline $5^{\text {th }} \min \leq 7$ & $08(9.64)$ & $04(4.82)$ & $04(4.82)$ & $<0.00001$ \\
\hline $5^{\text {th }} \min >7$ & $75(90.36)$ & $73(87.95)$ & $02(2.41)$ & \\
\hline \multicolumn{5}{|l|}{ Resuscitation at birth } \\
\hline No or minimal resuscitation & $64(77.11)$ & $64(77.11)$ & 00 & \\
\hline PPV (BMV) only & $13(15.66)$ & $11(13.25)$ & $02(2.41)$ & $<0.00001$ \\
\hline Endotracheal Intubation & $06(7.23)$ & $02(2.41)$ & $04(4.82)$ & \\
\hline
\end{tabular}

Table II: Distribution of observed underlying cause \& outcome among neonatal pneumothorax

\begin{tabular}{|c|c|c|c|c|}
\hline Underlying cause & $\begin{array}{l}\text { Total } \\
\mathrm{n}(\%)\end{array}$ & $\begin{array}{c}\text { Survival } \\
\mathrm{n}(\%)\end{array}$ & $\begin{array}{l}\text { Death } \\
\mathrm{n}(\%)\end{array}$ & $\mathrm{P}$ value \\
\hline RDS & $20(24.10)$ & 18 & 02 & \\
\hline Pneumonia & $07(8.43)$ & 06 & 01 & \\
\hline MAS & $04(4.82)$ & 02 & 02 & 0.235893 \\
\hline Severe Perinatal asphyxia & $03(3.61)$ & 02 & 01 & \\
\hline Total & $34(40.96 \%)$ & 28 & 06 & \\
\hline
\end{tabular}


Bangladesh Crit Care J March 2019; 7 (1): 12-19

Table III: Distribution and outcome on the basis of coexisting underlying disease.

\begin{tabular}{lcccc}
\hline Variables & $\begin{array}{c}\text { Total } \\
\mathrm{n}(\%)\end{array}$ & $\begin{array}{c}\text { Survival } \\
\mathrm{n}(\%)\end{array}$ & $\begin{array}{c}\text { Death } \\
\mathrm{n}(\%)\end{array}$ & $\begin{array}{c}\text { P value } \\
\text { Patients with coexisting disease }\end{array}$ \\
Patients without coexisting disease & $34(40.96 \%)$ & 28 & 06 & 0.00226 \\
Total & $49(59.04 \%)$ & 49 & 00 & $06(7.23)$
\end{tabular}

Table IV: Distribution \& outcome of neonates on basis of Characterization \& treatment of cases

\begin{tabular}{lcccc}
\hline Variables & Total n $(\%)$ & Survived n(\%) & Expired n (\%) & P value \\
& $83(100.00)$ & $77(92.77)$ & $06(7.23)$ \\
\hline
\end{tabular}

\section{Characterization of pneumothoraces}

Primary spontaneous

$\begin{array}{llll}49(59.04) & 49 & 00 & 0.002 \\ 34(40.96) & 28 & 06 & \end{array}$

Secondary to coexisting disease

$34(40.96)$

Localization of pneumothorax

Right

Left

Bilateral

Pneumothorax developed

$\leq 48 \mathrm{~h}$ post delivery

$>48 \mathrm{~h}$ post delivery

Treatment of pneumothoraces

Oxygen therapy ( by oxyhood)

Thoracentesis and CT drain and MV

Oxygen therapy \& thoracentesis with needle aspiration

Thoracentesis \& Chest tube drain

$\begin{array}{cccc}64(77.11( & 62 & 02 & 0.00011 \\ 16(19.28) & 14 & 02 & \\ 03(3.61) & 01 & 02 & \end{array}$

$\begin{array}{llll}60(72.29) & 57 & 03 & 0.205 \\ 23(27.71) & 20 & 03 & \end{array}$

$64(77.11)$

$16(19.28)$

$02(2.41)$

$01(1.20)$
64

$10 \quad 06$

$02 \quad 00$

01

00

Table V. Distribution and outcome on the basis of clinical complications \& management data

\begin{tabular}{|c|c|c|c|c|}
\hline Variables & $\begin{array}{l}\text { Total } \\
\mathrm{n}(\%)\end{array}$ & $\begin{array}{c}\text { Survival } \\
\mathrm{n}(\%)\end{array}$ & $\begin{array}{l}\text { Death } \\
\mathrm{n}(\%)\end{array}$ & $\mathrm{P}$ value \\
\hline Sepsis & $17(20.48)$ & 15 & 02 & \\
\hline Severe Hypotension & $07(8.43)$ & 04 & 03 & \\
\hline Sepsis with NEC & $01(1.20)$ & 01 & 00 & \\
\hline NEC with DIC & $01(1.20)$ & 01 & 00 & \\
\hline Sepsis with DIC and IVH & $01(1.20)$ & 00 & 01 & \\
\hline Total no. of neonates with complications & $27(32.53)$ & 21 & 06 & 0.00025 \\
\hline No complications & $56(67.47)$ & 56 & 00 & \\
\hline
\end{tabular}

Table VI: Distribution and outcome of neonates on basis of ventilator support.

\begin{tabular}{|c|c|c|c|c|}
\hline Variables & $\begin{array}{c}\text { Survived } \\
\mathrm{n}(\%)\end{array}$ & $\begin{array}{c}\text { Expired } \\
n(\%)\end{array}$ & $\begin{array}{l}\text { Total } \\
\mathrm{n}(\%)\end{array}$ & $\mathrm{P}$ value \\
\hline Neonates with ventilatory support & $10(62.50)$ & $06(37.50)$ & $16(100)$ & $<0.00001$ \\
\hline Neonates without ventilatory support & $67(100)$ & 00 & $67(100)$ & \\
\hline Total & $77(92.77)$ & $06(7.23)$ & $83(100)$ & \\
\hline
\end{tabular}




\section{Discussion:}

Neonatal pneumothorax (NP) is a life-threatening condition associated with a high incidence of mortality and morbidity ${ }^{34}$. Once a diagnosis of tension pneumothorax has been made, prompt treatment should be undertaken to prevent serious morbidity and mortality. In an unstable patient, rapid treatment usually necessitates needle thoracentesis with a small gauge needle in the second intercostal space in midclavicular line. This is then followed by a formal chest drain in the fourth or fifth intercostal space in midaxillary line.

In some studies, it was observed that the incidence of radiologic SP is $1 \%$ to $2 \%$ and symptomatic SP is $0.05 \%$ to $1 \%$ in all live births ${ }^{1,3,7}$. Our study has similar result. These findings near consistent with findings of Santos Silva Í et.al ${ }^{35}$ study; they found prevalence of pneumothorax was $1.5 \%$, varying from $2.4 \%$ to $0.9 \%$.

It is known that NP occurs more often in young males than in females ${ }^{36,37}$. This was similar in our study, where $57.83 \%$ of the patients were baby boy. This finding similar with the findings of Santos Silva Í et.al ${ }^{35}$ and Begum $\mathrm{M}^{38}$ study, they found males $60.4 \%$ and $59.18 \%$ respectively.

NP more observed in neonates who delivered by caesarean section ${ }^{39,40}$; after elective caesarean section, the baby is not stressed and often has 'wet lungs' followed by forced respiration that may lead to pneumothora ${ }^{39}$. In agreement with the literature ${ }^{39,40}$, we found $72.29 \%$ developed pneumothorax in neonates who delivered by caesarean section. Apiliogullari $\mathrm{B}^{7}(67 \%)$ and Begum $\mathrm{M}^{38}$ (71.4\%) also observed NP more common in neonates who delivered by caesarean section.

We observed NP more common in term (69.88\%), NBW (59.04\%) and AGA (81.93\%) neonates, this findings confirmatory to the study of Apiliogullari $\mathrm{B}^{7}$, where they found NP in term $(83 \%)$, and $\mathrm{BW}>2000 \mathrm{gm}(77 \%)$.

The analysis of demographic and perinatal data of different groups, showed statistically significant differences in APGAR score at 5 th minute $(\mathrm{p}=<0.00001)$ and in resuscitation at birth ( $p<0.00001)$, and data of other groups showed statistically insignificant. Santos Silva Í et.al ${ }^{35}$ also found statistically significant differences in Apgar score at 5th minute $(\mathrm{p}=$ $0.002)$ and in resuscitation at birth $(p<0.001)$. Statistically significant differences in Apgar score at 5th minute occurred due to the need of resuscitation at birth, which was found to be a precipitator.

As described in Tab. II \& III, there was a statistically significant difference among coexisting \& non coexisting pathologies and outcome $(\mathrm{p}=0.00226)$. RDS $(24.10 \%)$ was most common respiratory pathology followed by Pneumonia $(8.43 \%)$ and MAS (4.82\%). Beside respiratory pathology severe PNA (3.61\%) was the underlying cause as these neonates required vigorous resuscitation soon after birth. This finding was confirmatory to the study of Santos Silva Í et.al ${ }^{35}$, they found NP was significantly associated with RDS (30\%) followed by Pneumonia $(7.5 \%)$ and MAS $(3.8 \%)$ and Apiliogullari $\mathrm{B}^{7}$, they found RDS (43\%), MAS (17\%), and
PNA (3\%). Rates of the most common coexisting pathologies observed in the present study, i.e. RDS, Pneumonia and MAS, were similar to those published elsewhere ${ }^{9,41}$.

Pneumothorax occurs more frequently during the neonatal period than at any other time of life and is most often seen in first 3 days of life ${ }^{10,41,42}$. In agreement with the literature ${ }^{41,42}$, in the present study, NP developed in the first 48 hour $72.29 \%$. Apiliogullari $\mathrm{B}^{7}(80 \%)$ and Begum $\mathrm{M}^{38}(81.63 \%)$ also found similar findings in their study. This findings was statistically insignificant $(\mathrm{p}=0.205)$

Analysis of chest X-rays was the primary tool for the diagnosis of NP in the present study. Transillumination of the thorax was often helpful in the emergency diagnosis of pneumothorax; the affected side transmits excessive light and may reveal $\mathrm{NP}^{43},{ }^{44}$. Asymptomatic pneumothorax usually unilatera ${ }^{44}$. It has been reported that two thirds of unilateral pneumothorax involves the right lung and between $15 \%$ and $25 \%$ of pneumothorax cases are bilateral ${ }^{41}$. NP was mainly observed in the right lung $(77.11 \%$ ( in the present study $(\mathrm{p}=0.00011)$. This finding was similar to findings of Begum $\mathrm{M}^{38}(61.22 \%)$ \& near consistent with Apiliogullari B $\mathrm{B}^{7}$ (40\%), and Santos Silva Í et.al ${ }^{35}$ (46.3\%) study.

The treatment of pneumothorax is not fully defined. Symptomatic spontaneous pneumothorax is one of the main reasons for admission of neonates to the NICU. As most cases of SP present with mild respiratory distress, the management of SP with or without supplemental oxygen is invariably different between physicians ${ }^{45,46}$. Without a continued air leak, asymptomatic and mildly symptomatic small pneumothoraces require only close observation ${ }^{44}$. In this study we described 83 pneumothoraces, primary spontaneous in 49 (59.04\%) neonates and secondary in $34(4096 \%)(p=0.002)$. This was confirmatory to Santos Silva Í et.al ${ }^{35}$ findings (SP-57.5\%, secondary-42.5\%). However, 64 (77.11\%) received oxygen therapy, because pneumothoraces with very small size in chest $\mathrm{X}$-ray resolved spontaneously. The use of needle aspiration and chest tube are common options of treatment. Thoracentesis was performed in a total 19 (22.89\%) pneumothoraces, however this treatment wasn't effective in $17(20.48 \%)$ of them. Hence, thoracentesis only treated 2 $(2.41 \%)$ non-hypertensive pneumothoraces. It is known that, frequently, neonates treated with needle aspiration can require subsequent chest tube insertion ${ }^{34}$. In our study, 17 neonates required CT drain and / or MV, of which $64.70 \%(\mathrm{n}=11)$ neonates needed drains to be effectively treated $(p=<0.00001)$. This finding similar to the findings of Santos Silva Í et.al ${ }^{35}$, in their study $71.3 \%$ neonates needed drains to be effectively treated.

The use of mechanical ventilation and thoracentesis associated with chest tube insertion and coexisting clinical complications have been reported to be important factors that can affect the prognosis of $\mathrm{NP}^{13,47,48}$. We found Clinical data suggest that complications such as sepsis, severe hypotension, NEC, DIC, IVH can negatively affect immediate outcomes $(\mathrm{p}=0.00025)$. Mortality with chest tube along with respiratory support (MV) was $37.50 \%$ in this study $(\mathrm{p}=<0.00001)$. 
A total 83 neonates, the overall prevalence of death was $7.23 \%(n=6)$. All of mortality observed in the neonates who got mechanical ventilation along with chest tube insertion (37.50\%), this finding comparable of Begum $\mathrm{M}^{38}$ Study, in her study overall mortality was $15 \%$ \& mortality with chest tube along with respiratory support (MV) reached to $46.6 \%$. Apiliogullari $\mathrm{B}^{7}(55.56 \%)$ \& Abdul latif $\mathrm{MAK}^{49}$ (62.7\%) were also found higher rate of mortality than our study in those neonates required $\mathrm{MV}$ along with chest tube drainage. The appropriate management used in the NICU was probably the explanation for this result.

Hypotension, sepsis, DIC, IVH, MV and thoracentesis associated with chest tube insertion for tension pneumothorax were found to be predictors of mortality in newborns with pneumothoraces. Similar findings also identified as a predictor of mortality by others; Duong $\mathrm{HH}^{4}$, Ozer EA ${ }^{16}$ and Santos Silva Í et.al ${ }^{35}$. The limitations of this study are the retrospective and single centre design.

Conclusion: Pneumothorax is relatively frequent in the NICU. Its underlying clinical conditions \& predictors of mortality should be known in order to prevent \& treat this critical situation. Pneumothorax itself was a predictor of mortality, strong index of suspicion, prompt diagnosis by transillumination, needle decompression, urgent portable chest X-ray and immediate intervention is needed for life saving and better outcome.

Neonatal pneumothorax may develop during the neonatal period, especially in the presence of underlying clinical conditions. Neonates with coexisting diseases and clinical complications and required CT drain and respiratory support (MV), despite treatment, had a high mortality rate. Pneumothorax itself was a predictor of mortality, so that adequate and prompt management should be used for life saving \& better outcome.

\section{References:}

1. Smith J, Schumacher RE, Donn SM, Sarkar S: Clinical course of symptomatic spontaneous pneumothorax in term and late preterm newborns: Report from a large cohort. Am J Perinatol 2011, 28(2):163-168.

2. Ogata ES, Gregory GA, Kitterman JA, Phibbs RH, Tooley WH. Pneumothorax in the respiratory distress syndrome: Incidence and effect on vital signs, blood gases, and $\mathrm{pH}$. Pediatrics. 1976; $58: 177-83$.

3. Crowley MA. Neonatal Respiratory Disorders. In: Martin RJ, Fanaroff AA, Walsh MC (Eds.). Fanaroff and Martin's Neonatal-Perinatal Medicine: Diseases of the Fetus and Infant. 10th edition, vol.2. Philadelphia: Elsevier Saunders, 2014, 1113-36.

4. Duong HH, Mirea L, Shah PS, Yang J, Lee SK, Sankaran K. Pneumothorax in neonates: Trends, predictors and outcomes. J Neonatal Perinatal Med. 2014;7(1):29-38.

5. Katar S, Devecioglu C, Kervancioglu M, Ulku R. Symptomatic spontaneous pneumothorax in term newborns. Pediatr Surg Int. 2006;22(9):755-758.

6. Chernick V, Avery ME. Spontaneous Alveolar Rupture at Birth. Pediatrics. 1963; 32: 816-824.

7. Apiliogullari B, Sunam GS, Ceran S, Koc H. Evaluation of neonatal pneumothorax. J Int Med Res. 2011; 39(6): 2436-2440
8. Kitsommart R, Martins B, Bottino MN, Sant'Anna GM. Expectant management of pneumothorax in preterm infants receiving assisted ventilation: report of 4 cases and review of the literature. Respir Care. 2012; 57(5):789-93

9. Ovalı F: Hava kaçagi sendromlari. In: Neonatoloji (Dag ־aog `lu T, ed), Istanbul: Nobel Tip Kitabevi, 2000; pp 299- 303.

10. Seguier-Lipszyc E, Elizur A, Klin B. Management of primary spontaneous pneumothorax in children. Clin Pediatr (Phila) 2011; 50: $797-802$.

11. Yu VY, Wong PY, Bajuk B, Szymonowicz W. Pulmonary air leak in extremely low birth weight infants. Arch Dis Child. 1986; 61:239-41

12. Jones RM, Rutter N, Cooper AC, Pullan CR. Pneumothorax in neonatal period. Anaesthesia. 1983; 38:948-52.

13. Esme H, Dogru O, Eren S, Korkmaz M, Solak O. The factors affecting persistent pneumothorax and mortality in neonatal pneumothorax. Turk J Pediatr. 2008; 50: 242-6.

14. Ramesh Bhat Y, Ramdas V. Predisposing factors, incidence and mortality of pneumothorax in neonates. Minerva Pediatr. 2013; 65:383-8.

15. Colin AA, McEvoy C, Castile RG. Respiratory Morbidity and Lung Function in Preterm Infants of 32 to 36 Weeks' Gestational Age. Pediatrics. 2010; 126(1):115-28.

16. Ozer EA, Ergin AY, Sutcuoglu S, Ozturk C, Yurtseven A. Is pneumothorax size on chest $\mathrm{X}$-ray a predictor of neonatal mortality? Iran J Pediatr. 2013; 23(5):541-5.

17. MacDuff A, Arnold A, Harvey J; BTS Pleural Disease Guideline Group. Management of spontaneous pneumothorax: British Thoracic Society Pleural Disease Guideline 2010. Thorax. 2010;65(Suppl 2):ii18-31.

18. Pocivalnik M, Meheden SV, Griesmaier E, Trawöger R, Kiechl-Kohlendorfer U, Pichler G et al. Pneumothorax during mechanical ventilation - therapeutic options in term and preterm neonates. Klin Pediatr. 2013; 225(7):389-93.

19. MacDonald H, American Academy of Pediatrics. Committee on Fetus and Newborn. Perinatal care at the threshold of viability. Pediatrics. 2002; 110(5):1024-7.

20. Ballard JL, Khoury JC, Wedig K, Wang L, Eilers-Walsman BL, Lipp R. New Ballard Score, expanded to include extremely premature infants. J Pediatr. 1991; 119(3):417-23.

21. Fenton, T.R. and J.H. Kim, A systematic review and meta analysis to revise the Fenton growth chart for preterm infants. BMC Pediatr. $2013 ; 13: 59$

22. Tavares PN, Flor-de-Lima F, Soares H, Guimarães H. Early nCPAP versus intubation in very low birth weight infants. J Pediatr Neonat Individual Med. 2013;2(2):e020201.

23. Vergnano S, Menson E, Kennea N, Embleton N, Russell AB, Watts T.et al. Neonatal infections in England: the NeonIN surveillance network. Arch Dis Child Fetal Neonatal Ed. 2011; 96(1):F9-14.

24. Sweet DG, Carnielli V, Greisen G, Hallman M, Ozek E, Plavka R. et al. European Association of Perinatal M. European consensus guide- lines on the management of neonatal respiratory distress syndrome in preterm infants - 2013 update. Neonatology. 2013; 103(4):353-68.

25. Machado LU, Fiori HH, Baldisserotto M, Ramos Garcia PC, Vieira AC, Fiori RM. Surfactant deficiency in transient tachypnea of the newborn. J Pediatr. 2011; 159(5):750-4.

26. Nissen MD. Congenital and neonatal pneumonia. Paediatr Respir Rev. 2007; 8(3):195-203. 
27. El Shahed AI, Dargaville PA, Ohlsson A, Soll R. Surfactant for meconium aspiration syndrome in term and late preterm infants, Cochrane Database Syst Rev. 2014;(12):CD002054.

28. Laudy JA, Tibboel D, Robben SG, de Krijger RR, de Ridder MA, Wladimiroff JW. Prenatal Prediction of Pulmonary Hypoplasia: Clinical, Biometric, and Doppler Velocity Correlates. Pediatrics. 2002; 109(2):250-8

29. Gomella TL. Perinatal Asphyxia. Neonatology- Management, Procedures, On- Call Problems, Diseases, and Drugs. 17th ed. 2015; 805-806.

30. Cayabyab R, McLean CW, Seri I. Definition of hypotension and assessment of hemodynamics in the preterm neonate. J Perinatol. 2009;29(Suppl 2):S58-62.

31. Papile LA, Burstein J, Burstein R, Koffler H. Incidence and evolution of subependymal and intraventricular hemorrhage: a study of infants with birth weights less than 1,500 gm. J Pediatr. 1978;92(4):529-34.

32. Volpe JJ. Neurology of the newborn. 4th ed. Philadelphia: W.B. Saunders, 2001, pp. xiii, 912.

33. Walsh MC, Kliegman RM. Necrotizing enterocolitis: treatment based on staging criteria. Pediatr Clin North Am. 1986;33(1):179-201.

34. Litmanovitz I, Carlo WA. Expectant management of pneumothorax in ventilated neonates. Pediatrics. 2008; 122(5):975-9.

35. Santos Silva Í, Flôr-de-Lima F, Rocha G, Alves I, Guimarães H. Pneumothorax in neonates: a level III Neonatal Intensive Care Unit experience. J Pediatr Neonat Individual Med. 2016;5(2):e050220. doi: $10.7363 / 050220$.

36. Ngerncham S, Kittiratsatcha P, Pacharn P: Risk factors of pneumothorax during the first 24 hours of life. J Med Assoc Thai 2005; 88(8): $135-141$.

37. Katar S, Deveciog `lu C, Kervanciog `lu M. et al. Symptomatic spontaneous pneumothorax in term newborns. Pediatr Surg Int 2006; $22: 755-758$

38. Begum M, Haque ZSM, Hassan M, Mannan MA, Jahan N. Immediate outcome of neonate with pneumothorax. Journal of Paediatric Surgeons of Bangladesh.2014; 5(1):3-7.
39. Benterud T, Sandvik L, Lindemann R. Cesarean section is associated with more frequent pneumothorax and respiratory problems in the neonate. Acta Obstet Gynecol Scand 2009; 88: 359 -361 .

40. Horowitz K, Feldman D, Stuart B. Full-term neonatal intensive care unit admission in an urban community hospital: the role of respiratory morbidity. J Matern Fetal Neonatal Med 2011; 24: 1407 $-1410$.

41. Zenciroglu A, Aydemir C, Bas AY, Demirel N. Evaluation of predisposing and prognostic factors in neonatal pneumothorax cases. Tuberk Toraks 2006; 54: 152 - 156

42. Lim, HS, Kim H, Jin JY, Shin YL.Characteristics of pneumothorax in a neonatal intensive care unit. J. Korean Soc. Neonatal 2011; 18 : 257-264.

43. Buck JR, Weintraub WH, Coran AG. Fiberoptic transillumination: a new tool for the pediatric surgeon. J Pediatr Surg 1977; 12: 451 463.

44. Carlo W A. Extrapulmonary Air Leaks. In: Behrman RE, Kliegman RM, Stanton BF, St Geme JW, Schor NF, editors. Nelson Textbook of Pediatrics. 20th ed. Philadelphia: Elsevier; 2016. Vol (1): 865 867.

45. Roberts D, Wacogne I. Question 3 In patients with spontaneous pneumothorax, does treatment with oxygen increase resolution rate? Arch Dis Child. 2010;95(5):397-398.

46. Clark SD, Saker F, Schneeberger MT, Park E, Sutton DW, Littner Y. Administration of $100 \%$ oxygen does not hasten resolution of symptomatic spontaneous pneumothorax in neonates. J Perinatol. 2014;34(7):528-531.

47. Atıc1 A, Satar M, Narlı N.Mechanic ventilation in newborn. Çukurova Univ Tıp Fak Dergisi 1996; 2: 128 - 132.

48. Watkinson M, Tiron I. Events before the diagnosis of a pneumothorax in ventilated neonates. Arch Dis Fetal Neonatal Ed 2001; 85: $201-203$

49. Abdullatif MAK, Abdullatif DAK. Pneumothorax in neonatal intensive care unit in Cairo university Hospital. J. Egypt. Soc.Parasitol 2012; 42(2): 495-506. 